\title{
PEONIES: Comparative Study by Anatomy and TLC of Three Traditional Chinese Medicinal Plants
}

\author{
F. El Babili ${ }^{{ }^{*}}$, M. El Babili ${ }^{2}$, I. Fouraste ${ }^{3}$, C. Chatelain ${ }^{1}$ \\ ${ }^{1}$ Faculté des Sciences Pharmaceutiques, Laboratoire de BOTANIQUE, Toulouse, France \\ ${ }^{2}$ Université Claude Bernard, Lyon I, Institut Michel Pacha, La Seyne sur Mer, France \\ ${ }^{3}$ Faculté des Sciences Pharmaceutiques, Laboratoire de Pharmacognosie, Toulouse, France \\ Email: ${ }^{*}$ fatiha.el-babili@univ-tlse3.fr
}

Received September 23, 2013; revised November 2, 2013; accepted November 26, 2013

Copyright (C) 2013 F. El Babili et al. This is an open access article distributed under the Creative Commons Attribution License, which permits unrestricted use, distribution, and reproduction in any medium, provided the original work is properly cited.

\begin{abstract}
Anatomical and TLC study of three Chinese peonies were conducted to make a comparative analysis. Peonies (Paeonia suffruticosa (tree peony), Paeonia lactiflora (Chinese peony) and Paeonia veitchii (Chinese peony)) are traditionally used on the Qinghai-Tibet Plateau in China. Recent studies have shown that the peonies have different pharmacological activities and clinical applications. To distinguish these three species of peonies and ensure the safety and effectiveness in their use, the microscopic characteristics and chromatographic profile of their roots and the corresponding powder were studied. Plant materials sectioned and stained and the raw powder were studied with an optical microscope using standard techniques in microscopy. The results of microscopic features and TLC were described and illustrated. The three species have different microscopic characteristics and TLC profiles, which allow us to distinguish them. In fact, with the help of features semi-quantitative and qualitative, an identification key was developed in our work and illustrated with photos and a table. The aim of our work was to show that the optical microscopy and related techniques provide a achievable practicality, which can be applied without ambiguity to the authentication of species peonies.
\end{abstract}

Keywords: Peonies; Microscopic Identification; TLC; P. suffructicosa; P. lactiflora; P. vetchii

\section{Introduction}

Peonies are herbaceous perennials belonging to the family Paeoniaceae which consists of 96 species worldwide, mainly distributed in the alpine regions of Asia and Europe. China is a major production area of peonies, containing 73 species, 2 subspecies and 7 varieties. There are 3 species in Paeoniaceae that are used in traditional Chinese medicine (TCM) under the general heading of "Peony": Paeonia suffruticosa (tree peony), Paeonia lactiflora (Chinese peony) and Paeonia veitchii (Chinese peony). These three species of Chinese peonies are perennials and can reach heights of up to nine meters (the tree peony is a bit more). They have alternate and elliptic leaves and smooth edges worn smooth by stems bearing two or more flowers. The large flowers of the peony Chinese may have a range of colors and generally have a diameter of $4-6 \mathrm{~cm}$. The roots of all peonies are large, straight and firm and have an easily separable bark revealing an under layer powder during its removal [1].

*Corresponding author.
Peonies have provided useful drugs and attractive ornamental flowers for over 3000 years in China and at least 500 years in Europe [1]. For millennia, the peony root has been used to treat wounds, fungal infections and spasmodic pain in TCM. Recently, the peony root has received increasing attention in research, mainly in Japan and China. In Europe, the peony has also long been used, particularly for spasmodic [2].

There are three drugs produced from the Chinese peonies used in traditional Chinese medicine [3]. P. lactiflora roots without bark provide "Baishao" or "Radix paeoniae alba", referred to below as white peony. In fact, the root without bark of these same three plants provides "baishao" (white peony), although most often this medicine is derived from P. lactiflora.

The root bark of $P$. veitchii (and sometimes $P$. lactiflora) roots provides "Aba” or "Radix paeoniae rubra", also called red peony.

$P$. suffruticosa bark of root provides "Mudanpi" or “Cortex Paeonia moutan”, referred to below as tree peony. The color designation does not refer to the flowers of 
these plants (which are most commonly pink, red, purple, or white) but refer to the color of the root after processing.

Several studies suggest that red and white peonies can be beneficial for people suffering from atherosclerosis and/or hypertension [3-5]. These 2 peonies are traditionally used in Asia to treat people with chronic viral hepatitis [6,7]. Their biochemical analysis showed the presence of paeniflorine, a sedative alkaloid, analgesic and anticonvulsifiant, which could explain the ancient practice of "big medicine". P. officinalis also contains paenol, known for its analgesic, antispasmodic and antiinflammatory [8].

To solve the problem of identifying these three species, which are often difficult to distinguish because of their great similarity, the microscopic and TLC analysis is simple, economical and reliable. For reasons of safety, efficacy and quality control, we have developed a TLC and microscopic identification technique, systematic and detailed for the three species studied. Our study thus demonstrates that optical microscopy supplied by TLC allows authentication of the 3 studied peonies in a simple, not expensive and unambiguous way.

\section{Materials and Methods}

\subsection{Plant Material}

Samples of root washers or fragmented and powders have been provided by European Pharmacopeia:

Paeonia lactiflora Pall (Radix paeoniae alba or Chinese phonetic name: Baishao);

Paeonia veitchii Lynch (Radix paeoniae rubra or Chinese phonetic name: Aba);

Paeonia suffructicosa Andr. (Cortex paeonia moutan or Chinese phonetic name: Mudanpi).

\subsection{Preparing Slides}

Observations are based on microscopic studies of sectioned and stained material of tissues Transverse sections are prepared with a sliding microtome (MSE) and stained in alun carmine-green combination or Mirande reagent [9] during 2 to 3 minutes then washed with water. Following staining, the transverse sections are mounted on glass slides using glycerine gel. Powder observations were made using Chloral hydrate solution R. [10]. Observations were made with a LEICA Microsystems DMLB microscope, and pictures were taken with Digital Camera Power Shot S40 CANON photo-micrographic system. For the description we have used some help books [11,12].

\subsection{Comparative Study of Three Species of Peonies}

\subsubsection{Anatomical Analysis}

The dry materials were divided into appropriate sizes.
Samples of root, rhizome were sectioned on a microtome in slices thick. Mid regions of stem and the most mature region of the root and rhizome available were taken. Tissues were stained by alun carmine-green combination or Mirande reagent and finally mounted on glass slides using glycerine gel for observation. Some sections were not stained so that idioblasts and other deposits would not be destroyed or otherwise altered during processing. The samples of crude drug were powdered. Ten different slides from the same powder were observed. Microchemical reactions were applied with lactic reagent or Gazet reagent to study powders in order to reveal lignified elements such as wood fibres, sclerenchyma and calcium oxalate crystals. All representative microscopic features were recorded by colour photography.

\subsubsection{TLC Analysis}

An aliquot of methanol solution of Paeonia suffructicosa Andr., Paeonia veitchii Lynch, Paeonia lactiflora Pall. (101.28, 100.04 and $79.9828 \mathrm{mg} / \mathrm{mL}$, respectively, 40 $\mu \mathrm{L}$ ) was directly deposited (as spots or bands) onto the TLC plates. TLC plates were developed in a presaturated solvent chamber with toluene-ethyl acetate-formic acidmethylene chloride (10:12:6:12) as developing reagents until the solvent front reached $1 \mathrm{~cm}$ from the top of plates. The developed TLC plates were then removed from the chamber, and allowed to air-dry for $30 \mathrm{~min}$. Each TLC plate was then monitored under UV light at 254 and 366 nm.

\section{Results}

\subsection{Anatomical Analysis [Table 1]}

\subsubsection{Paeoniae Alba (Baishao) [Photos 1-12]}

The transverse section of the root, almost circular, stained with alun carmine-green combination or Mirande reagent shows various characteristic elements from the outer to the inner side:

Cork shows a very broad, well developed zone composed of 8 - 10 layers of elongated tangentially reddishbrown cells with suberized walls. Cork tears in places giving rise to a kind of cones. Cork cambium is composed of 2 - 3 layers of more or less collapsed meristematic cells. Phelloderm consists of single-layered cells. Cortical parenchyma consists of numerous layers of elongated thin-walled cells, scattered air-spaces and is invaded by calcium oxalate crystals and numerous thick walled fibres, singly or grouped, with a narrow lumen, in its outermost area.

Phloem occupies unless than $13 \%$ of the transverse section. Each phloem patch contains small groups of sieve tubes, parenchyma and a few fibres separated by medullary rays. Cambium is a distinct zone of 2 - 3 layers of small meristematic cells. Xylem is a broad radiate 
Table 1. Key authentication and comparison parameters of the three species of Chinese paeony.

\begin{tabular}{|c|c|c|c|}
\hline Cell specification & $\begin{array}{l}\text { P. Iactiflora } \\
\text { (alba) }\end{array}$ & $\begin{array}{c}\text { P. veitchii } \\
\text { (rubrae) }\end{array}$ & $\begin{array}{l}\text { P. suffructicosa } \\
\text { (moutan) }\end{array}$ \\
\hline $\begin{array}{l}\text { Root transverse section } \\
\text { General view }\end{array}$ & almost circular & almost circular & almost circular \\
\hline Scale bar & $100 \mu \mathrm{m}$ & $235.29 \mu \mathrm{m}$ & $133.3 \mu \mathrm{m}$ \\
\hline cork & $150 \mu \mathrm{m}$ & $<100 \mu \mathrm{m}$ & $250 \mu \mathrm{m}$ \\
\hline Cortical parenchyma & Occupying less than $1 / 3$ & Occupying up to $1 / 3$ & Occupying almost $1 / 2$ \\
\hline $\begin{array}{l}\text { Lignified fibres } \\
\text { thick walled }\end{array}$ & $\begin{array}{l}112.5 \mu \mathrm{m} \text { large; } 150 \mu \mathrm{m} \text { long } \\
\text { Isolated or grouped; Present only in cortex }\end{array}$ & Absent & $\begin{array}{l}27.5 \mu \mathrm{m} \text { large grouped present } \\
\text { in all parenchyma }\end{array}$ \\
\hline calcium oxalate crystals & $11-35 \mu \mathrm{m}$ in diameter & $20-25 \mu \mathrm{m}$ & $25-33 \mu \mathrm{m}$ \\
\hline $\begin{array}{l}\text { Vascular bundle } \\
\Rightarrow \quad \text { Xylem }\end{array}$ & $\Rightarrow \quad \begin{array}{c}\text { Xylem rays (fibres and parenchyma } \\
\text { alternately arranged) }\end{array}$ & $\begin{array}{c}\Rightarrow \quad \text { Xylem rays (10 - } 30 \\
\text { rows of fibres and } \\
\text { parenchyma alternately } \\
\text { arranged) }\end{array}$ & $\Rightarrow$ narrow \\
\hline$\Rightarrow$ phloem & narrow & $\Rightarrow$ narrow & $\Rightarrow \quad$ Large (rays 1 - 3 cells wide) \\
\hline Starch & $\begin{array}{c}\text { Masses of gelatinized starch grains fairly } \\
\text { abundant }\end{array}$ & Simple starch granules & $\begin{array}{l}14 \mu \mathrm{m} \text { Abundant starch grains } \\
\text { in parenchymatous cells }\end{array}$ \\
\hline
\end{tabular}

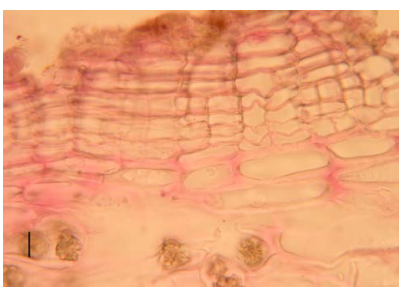

(1)

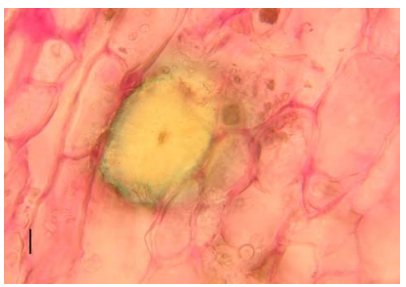

(5)

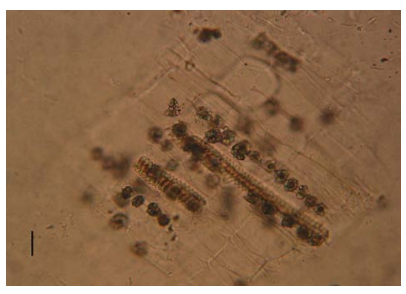

(9)

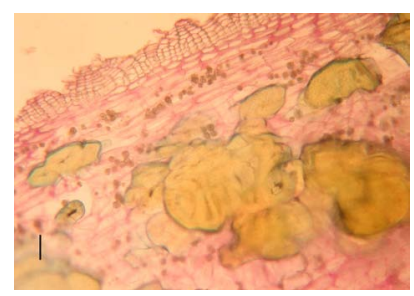

(2)

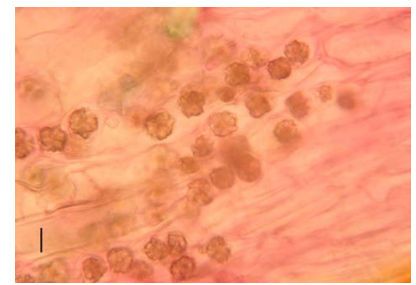

(6)

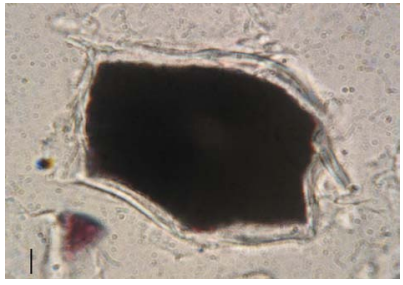

(10)

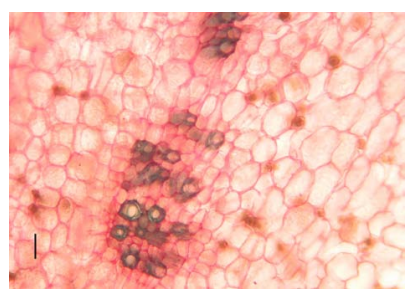

(3)

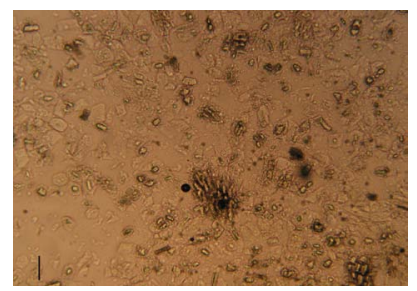

(7)

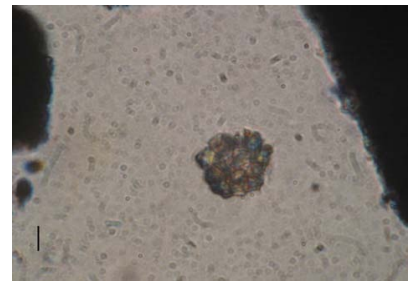

(11)

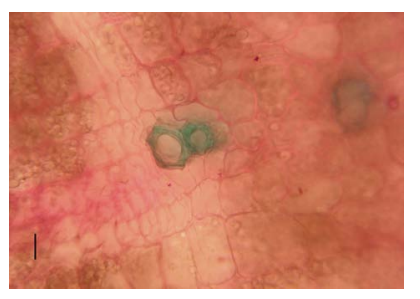

(4)

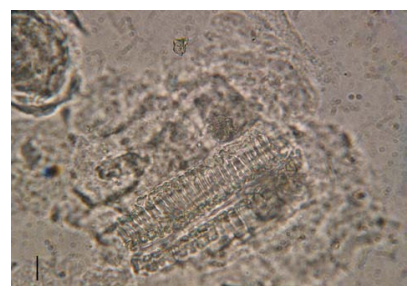

(8)

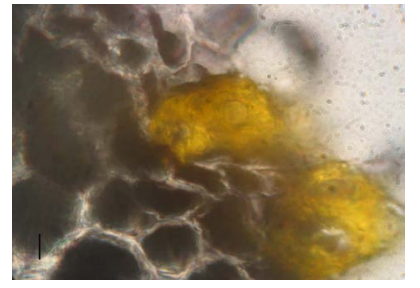

(12)

Photos 1-12. Paeonia alba (Paeonia lactiflora Pall.): (1)-(5): transverse sections and (7)-(12): ground powder. Scale bars: (1): 104.1 $\mu \mathrm{m}$; (2): $54.3 \mu \mathrm{m}$; (3): $25 \mu \mathrm{m}$; (4): $29.6 \mu \mathrm{m}$; (5): $20.83 \mu \mathrm{m}$; (6): $250 \mu \mathrm{m}$; (7): $25 \mu \mathrm{m}$; (8): $19.2 \mu \mathrm{m}$; (9): $9.85 \mu \mathrm{m}$; (10): 8.07 $\mu \mathrm{m}$; (11): $9.2 \mu \mathrm{m}$. (1) cork; (2) fibers; (3) vascular bundle; (4) vessels; (5) thick walled fibre; (6) calcium oxalate crystals; (7) general view; (8) spiral trachea of wood; (9) bundle surrounded by rows of calcium oxalate crystals; (10) gelatinized starch grains masses in parenchyma cell; (11) calcium oxalate crystal; (12) grouped fibres. 
zone, composed of wedge-shaped xylem patches consisting of radially elongated groups of spiral trachea and wood parenchyma. Each xylem patch is separated from its neighbour by large starchy medullary rays. Pith is completely resolved at its centre.

Clusters calcium oxalate crystals and masses of gelatinized starch grains are numerous in parenchyma cells, occurring always in the regions of cortex, phloem, xylem and pith.

$\underline{\text { Powder }}$

Examined under a microscope in the lactic $\mathrm{R}$ reagent, the Baishao powder, reddish brown, shows reddishbrown cells with suberized walls of cork, elongated thinwalled cells of parenchyma, calcium oxalate crystals and numerous thick walled fibres, spiral trachea of wood and masses of gelatinized starch grains in parenchyma cells.

\subsubsection{Paeoniae rubra (Aba) [Photos 13-22]}

The transverse section of the root, almost circular, stained with alun carmine-green combination or Mirande reagent shows various characteristic elements from the outer to the inner side:

Cork tears in places. Phelloderm consists of singlelayered cells. Cortical parenchyma consists of numerous layers of elongated thin-walled cells, separated by intercellular spaces and invaded by starch granules. There are no thick walled fibres.

Occupying unless than $25 \%$ of the transverse section, phloem is composed of sieve tube and phloem cells. Each phloem patch contains small groups of sieve tubes, parenchyma and a few fibres and formed shaped cones separated by medullary rays. Cambium, distinct, is constituted of 2 - 3 distinct layers of small meristematic cells. Xylem is a broad radiate zone, composed of wedgeshaped xylem patches consisting of radially elongated groups of spiral trachea and wood parenchyma. Each xylem patch is separated from its neighbour by narrow starchy medullary rays. Phloem and the medullar parenchyma are invaded by calcium oxalate crystals. Pith is completely reduced to its center.

\section{Powder}

Examined under a microscope in the lactic $\mathrm{R}$ reagent, the $\boldsymbol{A} \boldsymbol{b a}$ powder, slightly brown, shows reddish-brown cells with suberized walls of cork, elongated thin-walled cells of parenchyma invaded by starch grains, calcium oxalate crystals and spiral trachea of wood.

\subsubsection{Paeonia moutan (Mudanpi) [Photos 23-34]}

The transverse section of the root, almost circular, stained with alun carmine-green combination or Mirande reagent shows various characteristic elements from the outer to the inner side:

Cork shows a very broad, well developed zone composed of 12 - 16 layers of tangentially-elongated, red- dish-brown cells with suberized walls. Phelloderm consists of single-layered cells. Cortex consists of numerous rows of elongated thin-walled cells, separated by intercellular spaces and invaded by calcium oxalate crystals scattered in whole zone. Its innermost zone is totally starchy. Lignified fibres thick walled, singly or grouped in 2 - 4, with a narrow lumen are present in a small amount especially in the phloem area.

Phloem is occupying up to $50 \%-60 \%$ of the transsverse section. Phloem is organized in alternating zone with Liberian cell walls thickened and non-thickened.

Cambium is not distinct. Xylem is a broad radiate zone composed of vessels and wood parenchyma. Each xylem patch is separated from its neighbour by large starchy medullary rays.

Powder

Examined under a microscope in the lactic $\mathrm{R}$ reagent, the Mudanpi powder, reddish brown, shows reddishbrown cells with suberized walls of cork, elongated thinwalled cells of parenchyma, calcium oxalate crystals, starch grains, lignified fibres thick walled, singly or grouped in 2 - 4, with a narrow lumen and spiral trachea of wood.

\subsection{TLC Analysis}

Methanol solutions of Paeonia suffructicosa Andr., Paeonia veitchii Lynch, Paeonia lactiflora Pall. were monitored by a TLC (Figure 1) method to highlight the chemical differences of these 3 extracts and to confirm botanical differentiation because this method gives quick access for detection and localization of compounds in complicated plant extracts.

\section{Discussion}

The comparative microscopic observations of plant organs, tissues and crude drug powder of the three species of peonies indicate that many of these anatomical characteristics are homologous. Accordingly, we drew up a generalized description to account for these similarities:

Cork tending to peel off; developed parenchyma, with scattered large intercellular air-spaces; numerous calcium oxalate crystals; parenchyma tissue cells filled with starch grains, but usually distinct; the vascular bundles, developed in root, open collateral type. However, different species possess the unique micro structural characteristics. The anatomy and micro-morphology of peonies also reflect the high degree of diversity, which can be taken as the identifying standard of peonies. The characteristics in Table $\mathbf{1}$ are a summary of key authentication and comparison parameters of these three species, in the present study.

Paeonia suffruticosa by its durability, excellent resistance to extreme climates (it supports cold as heat, 


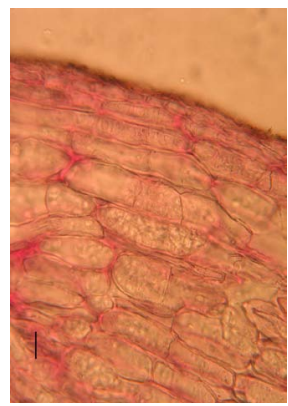

(13)

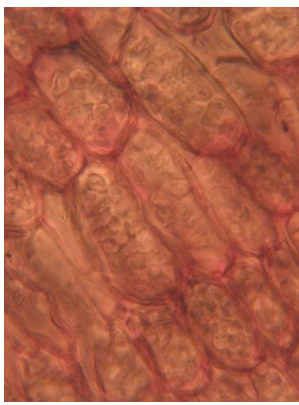

(18)

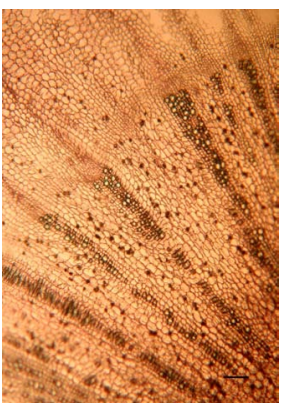

(14)

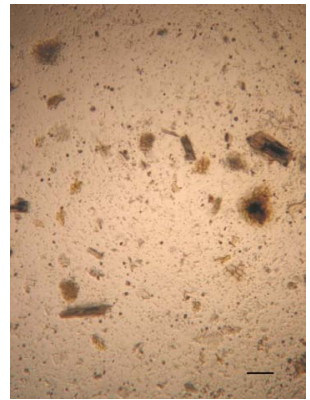

(19)

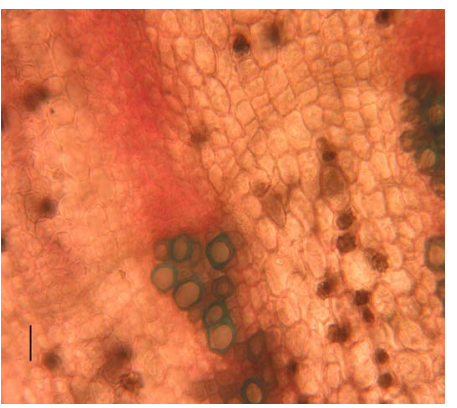

(15)

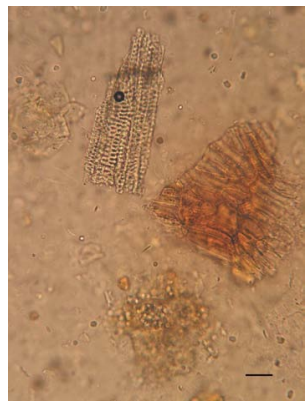

(20)

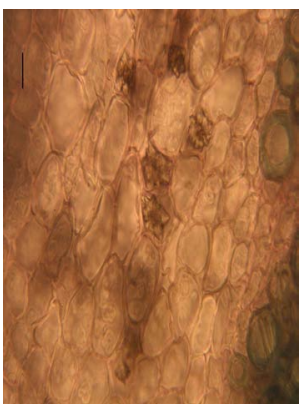

(16)

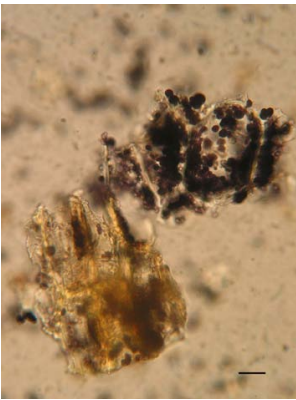

(21)

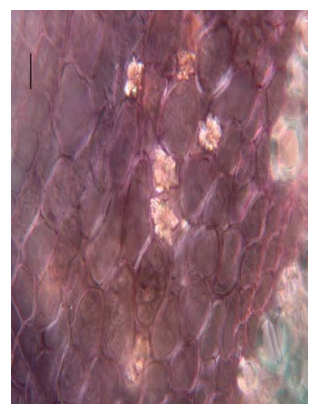

(17)

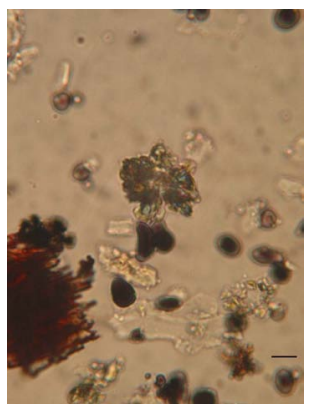

(22)

Photos 13-22. Paeonia rubrae (Paeonia veitchii Lynch). (12)-(17): transverse sections and (18)-(21): ground powder. Scale bars-(13) $53.57 \mu \mathrm{m}$; (14) $222.2 \mu \mathrm{m}$; (15) $28.57 \mu \mathrm{m}$; (16) $16 \mu \mathrm{m}$; (17) $16 \mu \mathrm{m}$; 18: $27.17 \mu \mathrm{m}$; (19) $250 \mu \mathrm{m}$; (20) $25 \mu \mathrm{m}$; (21) 21.87 $\mu \mathrm{m}$; (22) $8.33 \mu \mathrm{m}$. (13) thin cork; (14) cortical parenchyma; (15) cambial zone and vascular bundles; (16) calcium oxalate crystals under light; (17) calcium oxalate crystals under polarized light; (18) starch in parenchyma cells; (19) general view; (20) spiral trachea of wood and cork; (21) starch grains in parenchyma cell; (22) calcium oxalate crystal.

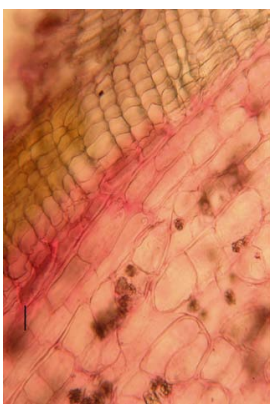

(23)

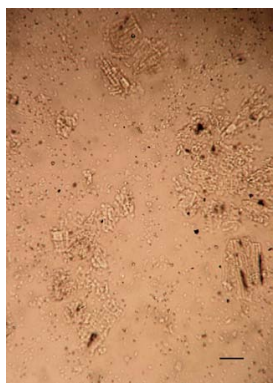

(29)

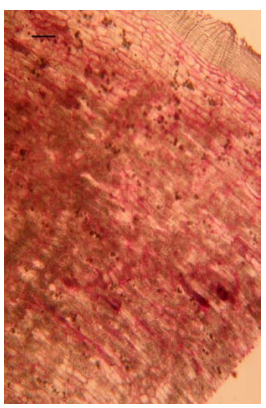

(24)

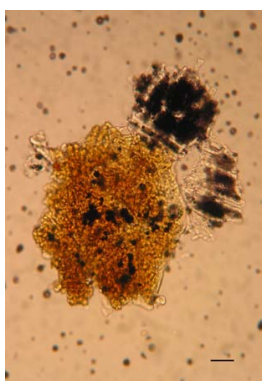

(30)

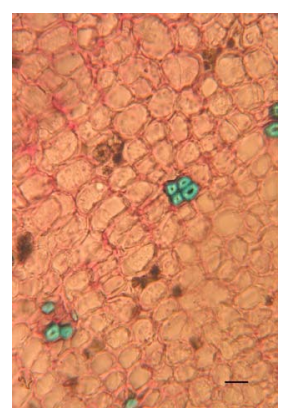

(25)

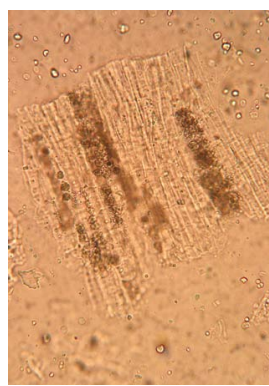

(31)

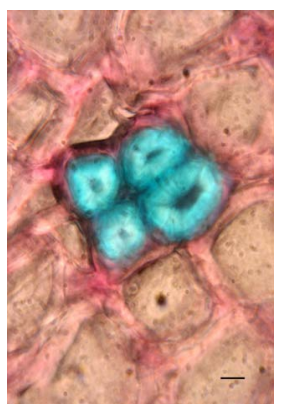

(26)

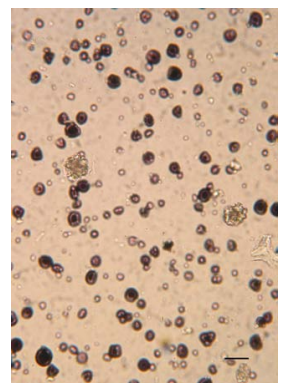

(32)

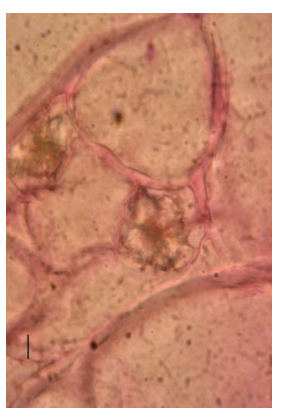

(27)

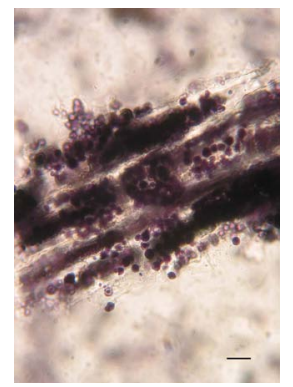

(33)

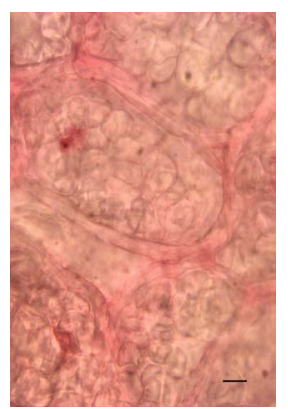

(28)

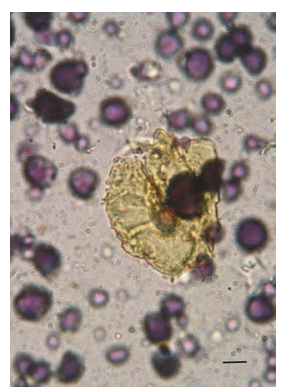

(34)

Photos 23-34. Paeonia mountan (Paeonia suffructicosa Andr.). (23)-(28): transverse sections; and (29)-(34): ground powder. Scale bars-(23) $37.71 \mu \mathrm{m}$; (24) $153.85 \mu \mathrm{m}$; (25) $50 \mu \mathrm{m}$; (26) $11.46 \mu \mathrm{m}$; (27) $11 \mu \mathrm{m}$; (28): $8 \mu \mathrm{m}$; (29) $314.3 \mu \mathrm{m}$; (30) $46.66 \mu \mathrm{m}$; (31) $47.22 \mu \mathrm{m}$; (32) $25 \mu \mathrm{m}$; (33) $35 \mu \mathrm{m}$; (34) $11.66 \mu \mathrm{m}$. (23) cork; (24) cortical parenchyma; (25) grouped fibres in parenchyma; (26) fibres; (27) calcium oxalate crystals; (28) starch in parenchyma cells; (29) general view; (30) cells with suberized walls of cork; (31) spiral trachea of wood with calcium oxalate crystal; (32) starch grains and calcium oxalate crystals; (33) starchy parenchyma; (34) lignified fibre thick walled. 

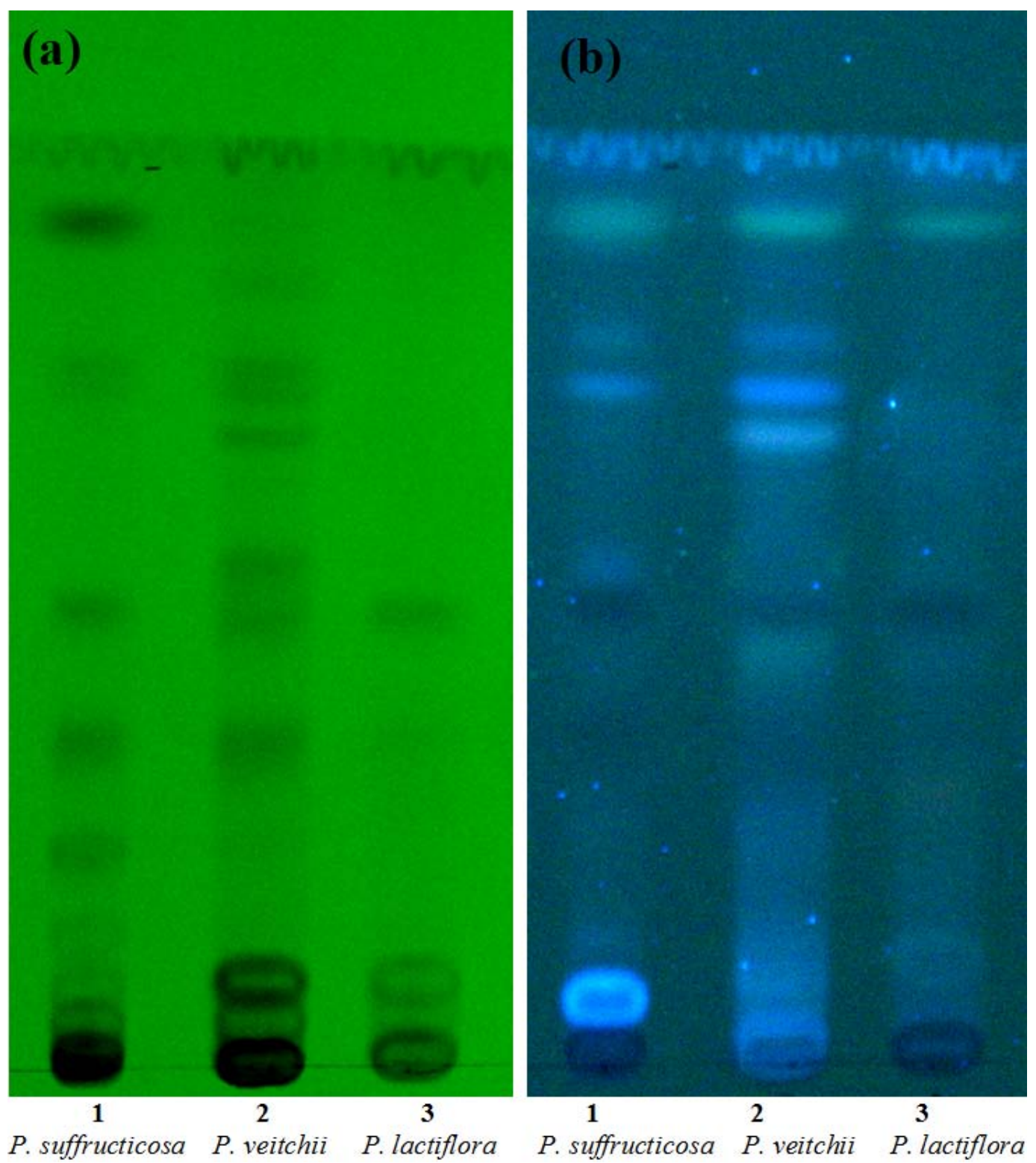

Figure 1. TLC plates visualized (A) under UV $254 \mathrm{~nm}$, and (B) under UV $366 \mathrm{~nm}$. $40 \mu$ l of methanol extract of Paeonia suffructicosa Andr. (1), Paeonia veitchii Lynch (2), Paeonia lactiflora Pall. (3) were applied as bands on TLC layers respectively.

drought and humidity) is a very interesting herb.

Indeed, the peonies have a very strong ability to survive in a hostile environment (cold, hypoxia, etc.). The microscopic comparison of three species shows that their structures are closely related to specific functions to adapt to their environment. For example, large quantities of idioblasts are not only important in resistance to drought and physiological cold, but also play an important role in resistance to ultraviolet rays and in protecting plants against damage. In addition, because of the characteristics of air and soil in the highlands, the peonies have developed a wood to withstand strong winds. Consequently, a microscopic analysis of the internal structure of peonies can contribute greatly to our understanding of adaptation strategies to environmental extremes. Through the comparative study of the anatomy and micromorphology of three species, we hope to ensure their safety and efficacy.

A bio-guided phytochemical study will be underway to characterize the components and identify those that are biologically and chemically active (antioxidants, inhibitor of XO, anti-MCF7) extracts TLC.

\section{REFERENCES}

[1] S. Foster and C. X. Yue, "Herbal Emissaries: Bringing Chinese Herbs to the West," Healing Arts Press, Rochester, 1992, pp. 200-207. 
[2] M. Blumenthal, "The Complete German Commission E Monographs: Therapeutic Guide to Herbal Medicines,” Integrative Medicine Communications, Newton, 1998, p. 364.

[3] D. Bensky, A. Gamble and T. Kaptchuk, "Chinese Herbal Medicine Materia Medica,” Revised Edition, Eastland Press, Seattle, 1993, pp. 70-71,277-278,331-332.

[4] J. Liu, "Effect of Paeonia Obovata 801 on Metabolism of Thromboxane B2 and Arachidonic Acid and on Platelet Aggregation in Patients with Coronary Heart Disease and Cerebral Thrombosis,” Chung Hua I Hsueh Tsa Chih, Vol. 63, 1983, pp. 477-481.

[5] T. L. Guo and X. W. Zhou, "Clinical Observations on the Treatment of the Gestational Hypertension Syndrome with Angelica and Paeonia Powder," Chung Hua I Hsueh Tsa Chih, Vol. 6, 1986, pp. 714-716,707.

[6] D. G. Yang, “Comparison of Pre- and Post-Treatment Hepatohistology with Heavy Dosage of Paeonia Rubra on Chronic Active Hepatitis Caused Liver Fibrosis,” Chung Hua I Hsueh Tsa Chih, Vol. 14, 1994, pp. 207-209,195.
[7] C. B. Wang and A. M. Chang, "Plasma Thromboxane B2 Changes in Severe Icteric Hepatitis Treated by Traditional Chinese Medicine-Dispelling the Pathogenic Heat from Blood, Promoting Blood Circulation and Administrating Large Doses of Radix Paeoniae-A Report of 6 Cases,” Chung Hua I Hsueh Tsa Chih, Vol. 5, 1985, pp. 326-328,322.

[8] B. Boullard, "Dictionnaire des Plantes Médicinales du Monde: Réalités \& Croyances,” Estem, 2001.

[9] R. Mirande, "Sur le Carmin Aluné et son Emploi, Combiné avec celui du vert D’iode, en Histologie végétale,” CR Academic Science, Vol. 170, 1920, pp. 197-199.

[10] "European Pharmacopoeia (in Force)," Maison Neuve Moulins, les Metz.

[11] A. Speranza and G. L. Calzoni, "Atlas de la structure des plantes,” Belin, 2005, pp. 125-203.

[12] Z. Y. Chen, Y. T. Chen and D. H. Wang, "HPLC Determination of Salidroside in the Roots of Rhodiola Plants," China Journal of Chinese Materia Medica, Vol. 11, 2006, pp. 939-941. 